\title{
Low Temperature Synthesis of $\beta$-SiC Powder by the Na Flux Method using Fullerene and Silicon
}

\author{
Fumihiro KAWAMURA, Hisanori YAMANE, Takahiro YAMADA, Shu YIN and Tsugio SATO \\ Institute of Multidisciplinary Research for Advanced Materials, Tohoku University, 2-1-1, Katahira, Aoba-ku, Sendai-shi $980-8577$ \\ フラーレンとシリコンを用いた Na フラックス法による $\beta$-SiC 粉末の低温合成 \\ 川村文洋・山根久典・山田高広・殷 シュウ・佐藤次雄 \\ 東北大学多元物質科学研究所, 980-8577 仙台市青葉区片平 2-1-1
}

\begin{abstract}
Silicon carbide $(\mathrm{SiC})$ powder was prepared by heating a mixture of fullerene and silicon powders at $900-1000 \mathrm{~K}$ for $24 \mathrm{~h}$ with a $\mathrm{Na}$ flux. $\mathrm{X}$-ray and electron diffraction revealed that the obtained powder was $\beta$-SiC. The agglomerates of $\mathrm{SiC}$ particles with a size of a few dozen $\mathrm{nm}$ were observed by transmission electron microscopy. The specific surface area and mean particle size of the $\mathrm{SiC}$ powder prepared at $1000 \mathrm{~K}$ were $12 \mathrm{~m}^{2} / \mathrm{g}$ and $88 \mathrm{~nm}$, respectively.

[Received August 28, 2006; Accepted November 16, 2006]
\end{abstract}

Key-words : SiC, Low temperature synthesis, Nano-particle, Fullerene, Na flux

1. Introduction

Since $\mathrm{SiC}$ has excellent properties of high strength, hardness, corrosion resistance and stability even at high temperatures and in acid solutions, $\mathrm{SiC}$ powder and ceramics have been used not only for high temperature structural materials but also for other applications such as catalyst carrier and support. ${ }^{1)} \mathrm{SiC}$ powder has been widely produced by using the Acheson process, ${ }^{2)}$ in which the carbothermic reaction of $\mathrm{SiO}_{2}$ with carbon powder is carried out at temperatures around 2500-2700 K for several hours. Due to the high reaction temperatures and long reaction times of the process, the prepared powder has a large particle size and mostly consists of $\alpha$-SiC. It is usually difficult to sinter the $\mathrm{SiC}$ powder without sintering aids or pressure due to its covalent bonding. ${ }^{3), 4)}$ However, using a fine and high purity powder, well-sintered $\mathrm{SiC}$ bodies can be produced with fewer additives under a lower pressure. ${ }^{5)}$

Fine $\mathrm{SiC}$ powder is synthesized by pyrolysis of organosilicon compounds, such as polycarbosilane and dimethyldichlorosilane, at $\left.1300-1800 \mathrm{~K}^{6}{ }^{6}, 7\right)$ Reaction of silane or tetrachlorosilane with hydrocarbons was carried out at around 1400$1700 \mathrm{~K}$ for the chemical vapor deposition of $\mathrm{SiC}$ powder. ${ }^{8), 9)}$ $\mathrm{As} \mathrm{Hu}$ et al. introduced in their report, ${ }^{10)} \mathrm{SiC}$ powders have also been synthesized by various other techniques such as self-propagating high-temperature synthesis (SHS), sol-gel method, plasma-, and microwave-radiation methods.

Recently, epitaxial $\beta$-SiC films were grown on $\mathrm{Si}$ (100) substrates at $950-1250 \mathrm{~K}$ under ultra-high vacuum conditions by using fullerene $\left(\mathrm{C}_{60}\right.$ and $\left.\mathrm{C}_{70}\right)$ as an active carbon source. ${ }^{11), 12)}$ The nano-size $\beta$-SiC powder and nanowires were synthesized at $873-973 \mathrm{~K}$ by the reduction of tetrachlorosilane or carbon tetrachloride with $\mathrm{Na}$ in a titanium alloy autoclave. ${ }^{10), 13)}$ The reactions are represented by the following formulas:

$$
\begin{aligned}
& \mathrm{CCl}_{4}+4 \mathrm{Na}+\mathrm{Si} \longrightarrow \mathrm{SiC}+4 \mathrm{NaCl} \\
& \mathrm{SiCl}_{4}+4 \mathrm{Na}+\mathrm{C} \longrightarrow \mathrm{SiC}+4 \mathrm{NaCl}
\end{aligned}
$$

It was expected that $\mathrm{Na}$ acts not only for the reducer but also a flux.

In the present study, we prepared $\beta$-SiC powder at $900-$ $1000 \mathrm{~K}$ by the Na flux method using fullerene and silicon powders instead of the chloride of $\mathrm{SiCl}_{4}$ or $\mathrm{CCl}_{4}$ as starting materials, and characterized the obtained powder.

\section{Experimental}

Si powder (Mitsuwa Chemicals, 99.999\% purity, 200mesh,) and fullerene powder (Frontier Carbon, C60: 60\%, C70: $25 \%$, higher fullerenes: 15\%) or graphite powder (Alfa Chemical, 99.9995\% purity, 200-mesh) were weighed at a $\mathrm{Si}: \mathrm{C}$ molar ratio of $1: 1$, and mixed for about $20 \mathrm{~min}$ with an agate pestle and mortar in an Ar-gas filled glove box. About $50 \mathrm{mg}$ of the mixed powder was pressed into a pellet, and placed in a boron nitride crucible (Showa Denko, 99.5\%, inside diameter $6 \mathrm{~mm}$, depth $18 \mathrm{~mm}$ ) with about $150 \mathrm{mg}$ of $\mathrm{Na}$ (Nippon Soda, 99.95\% purity). The crucible was set in a stainless steel tube (SUS316, external diameter $10 \mathrm{~mm}$, length $100 \mathrm{~mm}$ ). The tube was sealed with stainless-steel caps in an Ar atmosphere. The sample was heated at prescribed temperatures and maintained the temperatures for $24 \mathrm{~h}$ with an electric furnace.

After the heating, the sample was cooled in the furnace by shutting off the electric power to the furnace. The SUS tube was cut in the glove box and the sample in the crucible was taken out from the tube. The $\mathrm{Na}$ metal including $\mathrm{SiC}$ powder reacted with the 2-propanol and ethanol. A dark gray fine powder suspended in alcohol-Na alkoxides solution was separated with a centrifuge. Distilled water was added to the powder and then the re-suspended powder was centrifuged again to remove any $\mathrm{Na}$ alkoxides or $\mathrm{NaOH}$ in the sample. This process was repeated 2 to 3 times, until the hydrogen-ion concentration $(\mathrm{pH})$ changed to 7 . During these processes, the violent reactivity of $\mathrm{Na}$ to water or ethanol, and the strong base of the solution containing $\mathrm{Na}$ should be cautioned. Finally, the washed sample was dried at $350 \mathrm{~K}$ in air.

The crystalline phases of the as-prepared samples were identified by X-ray diffraction (XRD, RINT2200, $\mathrm{Cu} \mathrm{K} \alpha$ ) using a holder with a polyimide film window in order to keep the samples in an inert atmosphere during the measurement. The XRD pattern of the washed sample was measured in air with a standard powder sample holder.

The observation of the morphology and selected-area electron diffraction (SAD) for the washed powder sample were carried out with a transmission electron microscope (TEM, JEOL, JEM-2000EX). The distribution of the powder size was measured with a laser diffraction particle size analyzer 
Table 1. Reaction Conditions and Products

\begin{tabular}{cclll}
\hline $\begin{array}{c}\text { Sample Temperature } \\
\text { (K) }\end{array}$ & Source materials & $\begin{array}{l}\text { Products } \\
\text { as prepared }\end{array}$ & after washing \\
\hline A & 1000 & Fullerene, $\mathrm{Si}$ & $\mathrm{Si} \gg$ amorphous & \\
B & 1000 & Fullerene, $\mathrm{Si}, \mathrm{Na}$ & $\mathrm{Na}, \mathrm{SiC}$ & $\mathrm{SiC}$ \\
C & 900 & Fullerene, $\mathrm{Si}, \mathrm{Na}$ & $\mathrm{Na}$ & $\mathrm{SiC}, \mathrm{SiO}_{2}$, amorphous \\
D & 850 & Fullerene, $\mathrm{Si}, \mathrm{Na}$ & $\mathrm{Na}, \mathrm{NaSi}$ & $\mathrm{SiO}_{2}$, amorphous \\
E & 700 & Fullerene, $\mathrm{Si}, \mathrm{Na}$ & $\mathrm{Na}, \mathrm{NaSi}, \mathrm{Si}$ & $\mathrm{Si}^{\mathrm{SiO}}$, amorphous \\
F & 1000 & Graphite, $\mathrm{Si}, \mathrm{Na}$ & $\mathrm{Na}, \mathrm{NaSi}$ & Graphite, $\mathrm{SiO}_{2}$ \\
\hline
\end{tabular}

(Shimadzu, SALD-7000). The powder sample was also characterized with a specific surface area analyzer (Quantachrome, NOVA1000).

\section{Results and discussion}

Table 1 summarizes the reaction conditions and the results of phase identification by XRD for the as-prepared and washed samples. When the mixture of fullerene and Si powders was heated at $1000 \mathrm{~K}$ without $\mathrm{Na}, \mathrm{SiC}$ was not formed (sample A). The crystalline phase was Si only. A very weak broad diffraction peak was observed around $2 \theta=8-10^{\circ}$ and $15-20^{\circ}$, which suggests the amorphous phase derived from fullerene. The XRD pattern of the as-prepared sample of B indicated that the crystalline phases were $\mathrm{Na}$ and $\mathrm{SiC}$.

The XRD pattern of the washed sample $B$ is shown in Fig. 1. All broad diffraction peaks were indexed with the lattice parameter of $\beta$-SiC (cubic, $a=0.436 \mathrm{~nm}$ ). The relative intensities of the diffraction peaks were also consistent with those reported for $\beta$-SiC. ${ }^{14)}$ The crystallite size calculated by Scherrer's equation ${ }^{15)}$ with the full width at half maximum of the diffraction peaks was about $9 \mathrm{~nm}$.

The TEM image of sample B is shown in Fig. 2. It was observed that small particles with a size of $20-40 \mathrm{~nm}$ aggregated and formed secondary particles or agglomerates of a few hundred $\mathrm{nm}$. The SAD pattern from the agglomerates consisted of rings with some spots, which corresponded to the diffractions of $\beta$-SiC (111), (220) and (311) planes.

The distribution of particle size was measured for the washed sample B dispersed in water by ultrasonic agitation. The mean particle size of the sample was $88 \mathrm{~nm}$, and $10 \%$ diameter (D), 50\%D, and 90\%D are $67 \mathrm{~nm}, 87 \mathrm{~nm}$, and 116 $\mathrm{nm}$, respectively. The specific surface area of the sample analyzed by nitrogen gas adsorption was $12 \mathrm{~m}^{2} / \mathrm{g}$.

In the XRD pattern of the as-prepared sample of $\mathrm{C}$, diffraction peaks were from $\mathrm{Na}$. After the removal of $\mathrm{Na}$, a small amount of gray powder was obtained. The broad peaks of an amorphous phase and weak peaks of $\mathrm{SiC}$ were observed in the diffraction pattern. The formation of $\mathrm{SiC}$ at $900 \mathrm{~K}$ was confirmed from this result but the yield of $\mathrm{SiC}$ was small.

At and below $850 \mathrm{~K}, \mathrm{NaSi}$ formed in the $\mathrm{Na}$ melt. This phase is unstable and probably decomposed into $\mathrm{SiO}_{2}$ crystobalite during the process of $\mathrm{Na}$ removal with alcohol and water. In the XRD patterns of the washed samples of $C, D$ and E, a diffraction peak was observed at $2 \theta=21.5^{\circ}$, which corresponds to the largest diffraction peak of cristobalite $\mathrm{SiO}_{2}$. The weak broad diffraction peak was also observed around $2 \theta$ $=10^{\circ}$ in these XRD patterns. The fullerene probably changed into an amorphous phase at 700-900 K. Unreacted Si was contained in the sample prepared at $700 \mathrm{~K}$.

When graphite was used as a carbon source instead of fullerene, we could not obtain $\mathrm{SiC}$ powder at $1000 \mathrm{~K}$ by using a $\mathrm{Na}$ flux (sample F). The as-prepared sample contained $\mathrm{NaSi}$, and

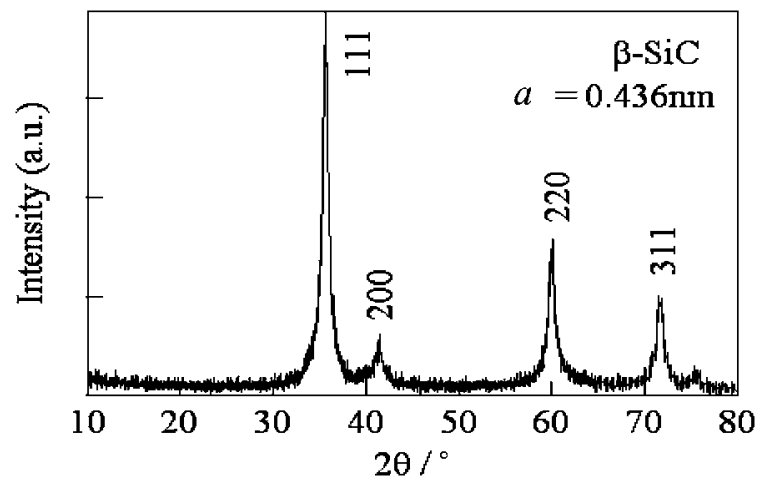

Fig. 1. XRD pattern of sample B after washing.

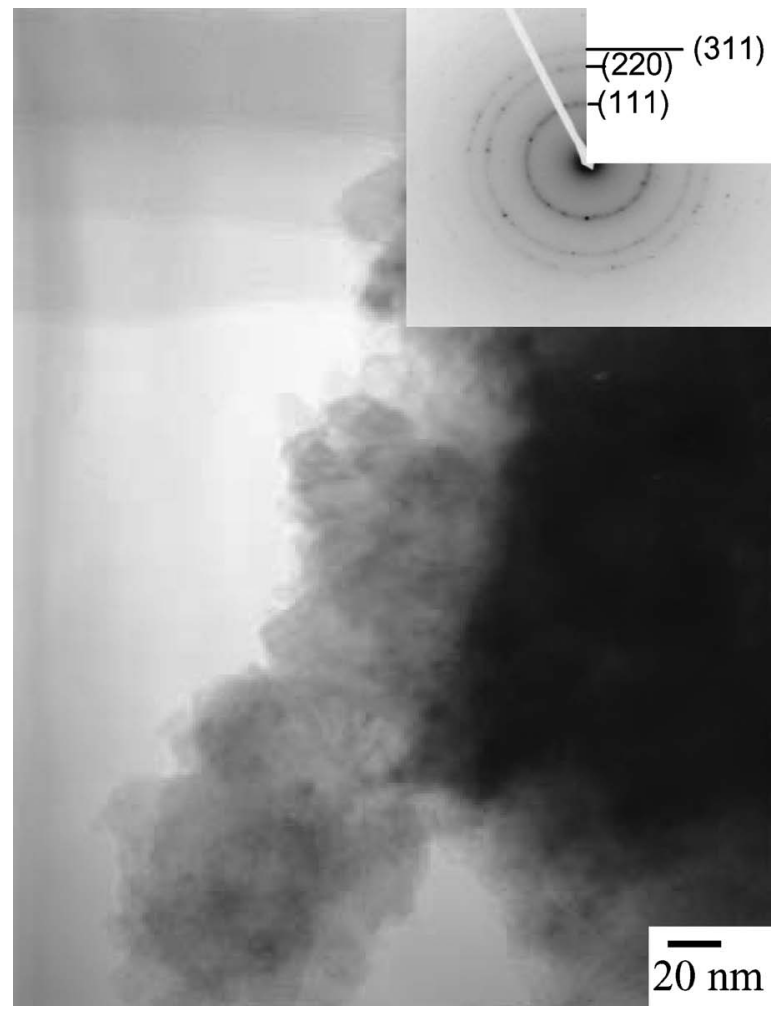

Fig. 2. TEM image and SAD pattern of sample B after washing.

after removal of $\mathrm{Na}$, a main peak of graphite was seen at $2 \theta=$ $26.4^{\circ}$ in addition to the peak of cristobalite in the XRD pattern.

It was reported that an $\mathrm{SiC}$ epitaxial layer was formed on the $\mathrm{Si}$ substrate by the reaction between $\mathrm{Si}$ substrate and $\mathrm{C}_{60}$ or $\mathrm{C}_{70}$ at $900-1000 \mathrm{~K}$ in an ultra-high vacuum. However, the formation of $\mathrm{SiC}$ powder by reaction of $\mathrm{Si}$ and fullerene powders was not detected at $1000 \mathrm{~K}$ without $\mathrm{Na}$ (sample A). The results of the samples prepared at 700-850 K suggested that $\mathrm{Na}$ and $\mathrm{Si}$ reacted and formed $\mathrm{NaSi}$ at a lower temperature before the formation of $\mathrm{SiC}$. However, graphite did not react with $\mathrm{NaSi}$ at $1000 \mathrm{~K}$ in the Na flux. Synthesis of SiC by the Na flux method using other reactive carbon sources such as glassy carbon or amorphous carbon is now under investigation.

\section{Conclusion}

$\beta$-SiC powder was prepared by heating the mixture of fulle- 
rene and Si powders for $24 \mathrm{~h}$ at $900-1000 \mathrm{~K}$ in a $\mathrm{Na}$ flux. The agglomerates of $\mathrm{SiC}$ small particles with a size of a few dozen nm were observed by TEM. It was demonstrated that fullerene was an active carbon source for the synthesis of $\mathrm{SiC}$ powder in a $\mathrm{Na}$ melt at $1000 \mathrm{~K}$.

Acknowledgements This study was supported in part by Science Research Expenses Subsidy from the Ministry of Education, Culture, Sports, Science and Technology, Grant-in-Aid for Exploratory Research, 18655083, 2006. The authors thank Dr. Mitsuo Suzuki of the Frontier Carbon Co., Ltd. for his helpful discussion.

\section{References}

1) Sōmiya, S. and Inomata, Y., "Silicon Carbide Ceramics-2," Elsevier Science (1991).

2) Enomoto, R., J. Ceram. Asoc. Jpn., Vol. 17, No. 10, pp. 828-833 (1982) [in Japanese].

3) Alliegro, R. A., Coffin, L. B. and Tinklepaugh, J. R., J. Am. Ceram. Soc., Vol. 39, pp. 386-389 (1956).

4) She, J. H. and Ueno, K., Mater. Res. Bull., Vol. 34, pp. 1629-1636 (1999).

5) Prochazka, S., "Proceedings of the Second Army Materials Technology Conference," Ed. by Burke, J. J., Gorum, A. E. and Katz, R. N., Brook Hill Publishing Co., Chestnut Hill, OH
(1975) pp. 239-252.

6) Narisawa, M., Shimoda, M., Okamura, K., Sugimoto, M. and Seguti, T., Bull. Chem. Soc. Jpn., Vol. 68, pp. 1098-1104 (1995).

7) Krishnan, V., Bindu, R., Chandrasekhar, V. and Murthy, V. S. R., J. Am. Ceram. Soc., Vol. 85, pp. 504-506 (2002).

8) Chen, L., Goto, T. and Hirai, T., J. Mater. Sci., Vol. 24, pp. 3824-3830 (1989).

9) Kavecky, S., Janekova, B., Madejova, J. and Sajgalik, P., J. Eur. Ceram. Soc., Vol. 20, pp. 1939-1946 (2000).

10) Hu, J.-Q., Lu, Q.-Y., Tang, K.-B., Qian, Y,-T., Zhou, G.-E., Liu, X.-M. and $\mathrm{Wu}$, J.-X., Chem. Mater., Vol. 11, pp. 2369-2371 (1999).

11) Hamza, A. V., Balooch, M. and Moalem, M., Surf. Sci., Vol. 317, pp. L1129-L1135 (1994).

12) Wang, X.-D., Xue, Q., Hashizume, T., Shinohara, H., Saito, Y., Nishina, Y. and Sakurai, T., Appl. Surf. Sci., Vol. 76/77, pp. 334-339 (1994).

13) Hu, J. Q., Lu, Q. Y., Tang, K. B., Deng, B., Jiang, R. R., Qian, Y. T., Yu, W. C., Zhou, G. E., Liu, X. M. and Wu, J. X., J. Phys. Chem. B, Vol. 104, pp. 5251-5254 (2000).

14) International Centre for Diffraction Data, File Card No. 73-1708.

15) Culity, B. D., “Elements of X-ray Diffraction,"Addison-Wesley Pub., Reading, Massachusetts (1978). 